\title{
THE CAPACITY FOR INCREASE IN CHROMOSOMALLY POLYMORPHIC AND MONOMORPHIC POPULATIONS OF DROSOPHILA PSEUDOOBSCURA
}

\author{
TH. DOBZHANSKY,* R. C. LEWONTIN + and O. PAVLOVSKY \\ The Rockefeller Institute, New York, and Department of Biology, \\ University of Rochester
}

Received 14.iv.64

\section{INTRODUCTION}

Most natural populations of Drosophila pseudoobscura are chromosomally polymorphic, since they contain two or more, up to eight, variant forms of the third chromosome. The polymorphism is maintained by a strong balancing selection. The intensity of this selection under natural conditions is attested by rapid changes in the relative frequencies of the chromosomal polymorphs which occur in some populations from season to season or from year to year. Experiments on populations kept in laboratory population cages show that the balancing selection operates, usually though not always, because the heterokaryotypes are superior in fitness to the homokaryotypes (a review in Dobzhansky, 1964). Experimental laboratory population cages can, however, be made either chromosomally polymorphic (consisting of heterokaryotypes as well as homokaryotypes), or chromosomally monomorphic, containing homokaryotypes only. The question that naturally arises is in what respects can the polymorphic populations be said to be fitter than, or superior to the monomorphic ones, if, indeed, they are superior at all.

Beardmore, Dobzhansky and Pavlovsky (1960) and Battaglia and Smith (1962) showed that, in experimental population cages, the polymorphic populations produced more individuals, and a greater biomass, than did the monomorphic ones given the same amounts of food. Moreover, the polymorphic populations showed, for several characters, lower variances than the monomorphic ones. Using a rather different technique, Dobzhansky and Pavlovsky (rg6r) and Strickberger (1963) arrived at a similar conclusion-polymorphic populations yield more flies and a greater biomass than do monomorphic ones.

All the experiments referred to above had in common that the experimental populations were maintained under highly competitive conditions. The size of those populations was limited by the amount of the food given; in the experiments of Beardmore, Dobzhansky and Pavlovsky and in those of Battaglia and Smith (l.c.), the competition

* Experimental work under Contract No. AT-(30-1)-3096, U.S. Atomic Energy Commission

$\dagger$ Statistical analysis under Contract No. AT-(30-1)-2620, U.S. Atomic Energy Commission.

$2 Q$ 
was most severe in the larval stage, while in those of Dobzhansky and Pavlovsky (1.c.) it was probably more severe in the adult stage. We now wish to enquire whether the polymorphic populations will conserve their superiority should the competition be relaxed. Suppose that these populations are given a supply of food and of other resources and conditions which, for a time, is not limiting; will polymorphic populations increase at rates different from monomorphic ones? What we wish to estimate is the statistic referred to as the "intrinsic rate of natural increase" (Lotka, 1925), "Malthusian parameter" (Fisher, I930), or "innate capacity for increase" (Andrewartha and Birch, I954).

Experimentally, this statistic must, working with Drosophila, be estimated indirectly, since it is hardly possible to provide an environment for an unimpeded growth of Drosophila populations even for a few generations. Birch, Dobzhansky, Elliott and Lewontin (1963) have evolved a technique for the estimation of this statistic in geographic races of the Australian species, Drosophila serrata. The following components of the capacity for increase are measured: (a) fecundity of the females at different ages, $(b)$ survival from egg to adult, $(c)$ duration of the development from egg to adult, $(d)$ longevity of the females. The present report concerns the capacity for increase in ten experimental populations of Drosophila pseudoobscura, four of them polymorphic and six monomorphic ones. The experiments were conducted at two temperatures, $25^{\circ}$ and $16^{\circ} \mathrm{C}$.; they were repeated after a time interval of more than one year, in order to see what effects the adaptation to living in the experimental population cages may have.

\section{THE EXPERIMENTAL POPULATIONS}

Two series of experimental populations were set up, one containing third chromosomes with Arrowhead (AR) and Pikes Peak (PP) gene arrangements derived from wild flies collected at Mather, in the Sierra Nevada of California, in summer of 1959, and the other with AR and Chiricahua $(\mathrm{CH})$ chromosomes from Piñon Flats, Mount San Jacinto, California, collected much earlier, namely in I949. The manner in which these populations were made is important. We maintain in our laboratory about a dozen strains homozygous for each gene arrangement derived from different wild flies collected in a given locality. The strains are kept in mass cultures, to minimise inbreeding. The founders of each experimental population are always $F_{1}$ hybrids between all the available strains containing the desired chromosomes. The experimental populations, whether chromosomally polymorphic or monomorphic ones, are thus always provided with an initial supply of genetic variability, and are never homozygous for the gene complex which was carried in any one ancestral chromosome.

The experimental populations were kept in wooden population cages, with glass tops and wire mesh sides, in incubators or in constant 
temperature rooms at $25^{\circ} \mathrm{C}$. The populations were started on the following dates:-

No. 183 , Polymorphic AR +PP .

9th February 1960

No. 204, Polymorphic AR +PP.

I6th December 1960

No. 205, Monomorphic PP

No. 206, Monomorphic AR

No. 207, Polymorphic AR +PP . 17 th December 1960 19th December 1960 23rd December 1960 23rd December 1960

No. 208, Monomorphic PP

No. 209, Monomorphic AR

No. 2 I I, Polymorphic AR +CH

No. 212 , Monomorphic AR

No. 213 , Monomorphic CH 29th December 1960 I4th March I 96 I 14th March 196 r I4th March 196r

The relative frequencies of the chromosomes with different gene arrangements in the polymorphic populations underwent changes, as shown in table I. From time to time a sample of I 50 larvæ was taken

TABLE 1

Changes in the frequencies of $A R, C H$ and $P P$ chromosomes in the polymorphic populations (in per cent.)

\begin{tabular}{|c|c|c|c|c|c|c|c|c|}
\hline \multirow{2}{*}{ Days } & \multicolumn{2}{|c|}{211} & \multicolumn{2}{|c|}{183} & \multicolumn{2}{|c|}{204} & \multicolumn{2}{|c|}{207} \\
\hline & AR & $\mathrm{CH}$ & AR & PP & AR & PP & AR & PP \\
\hline 0 & $50 \cdot 0$ & $50 \cdot 0$ & $50 \cdot 0$ & $50 \cdot 0$ & $50 \cdot 0$ & $50 \cdot 0$ & $50 \cdot 0$ & $50 \cdot 0$ \\
\hline 35 & $60 \cdot 3$ & $39 \cdot 7$ & $57 \cdot 0$ & $43^{\circ}$ & $59 \cdot 7$ & $40 \cdot 3$ & $59^{\circ} 0$ & $4^{1 \cdot 0}$ \\
\hline 70 & $68 \cdot 7$ & $3^{1} \cdot 3$ & $75 \cdot 3$ & 24.7 & $63 \cdot 3$ & $3^{6 \cdot 7}$ & $69 \cdot 3$ & $30 \cdot 7$ \\
\hline 105 & $69 \cdot 3$ & $30 \cdot 7$ & $83 \cdot 7$ & $16 \cdot 3$ & $74 \cdot 7$ & $25 \cdot 3$ & $75 \cdot 7$ & $24 \cdot 3$ \\
\hline 140 & $70 \cdot 7$ & $29 \cdot 3$ & $89^{\circ} 0$ & $11 \cdot 0$ & $81^{\circ} 0$ & $19^{\circ} 0$ & $77 \cdot 3$ & $22 \cdot 7$ \\
\hline 210 & $68 \cdot 7$ & $31 \cdot 3$ & - & - & $82 \cdot 0$ & $18 \cdot 0$ & $86 \cdot 7$ & $13 \cdot 3$ \\
\hline 280 & $68 \cdot 3$ & $31 \cdot 7$ & $85 \cdot 3$ & 14.7 & $89 \cdot 3$ & 10.7 & $86 \cdot 3$ & 13.7 \\
\hline $3^{65}$ & $71 \cdot 3$ & $28 \cdot 7$ & $85 \cdot 7$ & 143 & $90 \cdot 0$ & $10 \cdot 0$ & $9^{1 \cdot 0}$ & $9^{\circ} 0$ \\
\hline 427 & & & & & 93.7 & $6 \cdot 3$ & $90 \cdot 0$ & $10 \cdot 0$ \\
\hline 455 & $75 \cdot 7$ & $24 \cdot 3$ & $9^{1 \cdot 7}$ & $8 \cdot 3$ & & $\overline{6}$ & $\overline{0}$ & $\overline{6}$ \\
\hline 545 & $80 \cdot 0$ & $20 \cdot 0$ & $0 \overline{6 \cdot 0}$ & $\overrightarrow{4 \cdot 0}$ & $94^{\circ} \mathrm{O}$ & $6 \cdot 0$ & $93 \cdot 3$ & $6 \cdot 7$ \\
\hline $\begin{array}{l}3 / 2 \\
635\end{array}$ & $77 \cdot 3$ & $22 \cdot 7$ & - & T & $95 \cdot 7$ & $4 \cdot 3$ & $9^{1} \cdot 7$ & $8 \cdot 3$ \\
\hline $73^{\circ}$ & $80 \cdot 3$ & $19 \cdot 7$ & $95 \cdot 3$ & 4.7 & $96 \cdot 3$ & 3.7 & $97 \cdot 3$ & $2 \cdot 7$ \\
\hline 815 & - & - & & & $9^{6 \cdot 3}$ & $3 \cdot 7$ & $9^{8} \cdot 0$ & $2 \cdot 0$ \\
\hline 845 & $\overrightarrow{-}$ & - & $100 \cdot 0$ & 0 & & & - & - \\
\hline 905 & $78 \cdot 3$ & $21 \cdot 7$ & - & - & $98 \cdot 7$ & $1 \cdot 3$ & - & - \\
\hline
\end{tabular}

in every population, and the gene arrangements were scored in 300 chromosomes per sample. In population No. 2 I I a stable equilibrium has apparently been reached, with AR chromosomes at a frequency between 75 and 80 per cent., and $\mathrm{CH}$ between 20 and 25 per cent. In contrast to this, no equilibria were established in the populations 183 , 204 and 207; the PP chromosomes were eliminated or were close to elimination, and the populations became monomorphic for AR. This outcome is not surprising; $\mathrm{PP}$ is a relatively rare chromosome in California populations (Dobzhansky, I963), and it appears to form 
heterotic combinations with some, but not with all, types of chromosomes found there. This situation will be dealt with in more detail in another publication.

The first series of observations on the longevity and fecundity was started with flies hatching in the population cages Nos. 183 and 204209 in January and February of $196 \mathrm{I}$, and with the populations Nos. 2I I-2I3 in April and May of the same year. The populations (excepting No. 183) were at these times between one and two months old, and the flies used belonged to the first or to the second generation developing in the population cages. The chromosomes in the polymorphic populations were far from having reached their equilibrium frequencies. The second series of observations was started with the flies hatching in the population cages 12 to 17 months later, in 1962. The polymorphic populations were then approaching, although they had not quite reached, the equilibria, and the populations Nos. 183, 204 and 207 still had some PP chromosomes left. The two series were intended to represent the populations at the times when the selectional processes were operating in them and when these processes were close to completion.

\section{THE CAPACITY FOR INCREASE}

Although the estimates of the value $r_{m}$, the " innate capacity for increase", are derived from the data on the fecundity, longevity, viability and the development rate of the flies, it is convenient to begin our presentation with a consideration of this derived value. Lotka showed (1925) that a population growing with unlimited resources would approach a stable distribution of ages of individuals. When such a stable age distribution is reached, the population as a whole will grow at a constant geometric rate satisfying the differential equation:

$$
\frac{d \mathcal{N}}{d t}=r_{m} \mathcal{N}
$$

where $\mathcal{N}$ is the size of the population at any instant of time and $r$ is the "rate of increase".

Lotka further showed that the rate of increase, $r$, in a population with a stable age distribution will be related to the age specific fecundity and mortality schedules by the following expression

$$
\int_{0}^{\infty} e^{-r_{m} x} l_{x} m_{x} d x=\mathbf{I}
$$

where 0 to $\infty$ is the range of possible ages, $l_{x}$ is the probability at birth of being alive at age $x$, and $m_{x}$ is the number of female offspring produced per unit time at age $x$. This latter quantity is taken as half the number of eggs laid per unit time.

We use expression (2) to estimate $r_{m}$ in our experiments by replacing the integration over continuous time by a summation over discrete 
time intervals. The exact form of the expression used to estimate $r_{m}$ is

where

$$
a \sum_{0}^{t} e^{-r m(x+F)} l_{x} m_{x}=\mathbf{I}
$$

$a=$ proportion of eggs surviving to adults

$t=$ observed maximum life span of our experimental animals

$l_{x}=$ probability of survival of adults from hatching from the pupal case to age $x$

$m_{x}=$ one half the number of eggs laid by a female of age $x$

$x=$ age, in days, of an adult calculated from date of hatching from the pupal case

$F=$ number of days from egg to pupal hatching

$r_{m}=$ intrinsic rate of increase.

The value of $r_{m}$ satisfying this expression is obtained by Newton's iterative method accurate to three decimal places. As expression (3) is written, it can be seen to be a function of four measurable quantities: development time from egg to adult $(F)$, egg, larval and pupal survival (a), the proportion of adults still alive at age $x\left(l_{x}\right)$, and the number of eggs laid by a female on day $x$ of her adult life $\left(m_{x}\right)$. We have made independent replicated estimates of each of these quantities and then combined these quantities to calculate $r_{m}$. Birch, Dobzhansky, Elliot and Lewontin (1963) have discussed the statistical problems involved in combining these independent estimates. In essence, we have calculated $r_{m}$ for every possible combination of replicated values of $a$, $F, l_{x}$ schedule and $m_{x}$ schedule, and used the mean and variance of these combinations as an estimate of the mean $r_{m}$ and variance of $r_{m}$. This, of course, is done separately for each population in each year. If there are io replicates of each of the four measurements then there will be 10,000 separate values of $r_{m}$ calculated from which the variance of $r_{m}$ is derived. However, these 10,000 values are not all independent so that the degrees of freedom associated with such a variance in statistical tests will be very much smaller than 9999 . We take as a conservative value for degrees of freedom $\Sigma\left(n_{i}-\mathrm{I}\right)$ where $n_{i}$ is the number of replicates of the $i$ th component of the rate of increase. In the case where each component is measured in Io replicates, there would then be 36 degrees of freedom associated with each variance in any test of significance.

Table 2 gives the means and variances of $r_{m}$ calculated in this way for each of the populations in each year and temperature, together with the number of degrees of freedom to be associated with each variance. The numbers of replicates of each component which contribute to these degrees of freedom are given in the discussions of each type 


\section{TH. DOBZHANSKY, R. C. LEWONTIN AND O. PAVLOVSKY}

of measurement below. Inspection of table 2 shows that at $16^{\circ}$ the values of $r_{m}$ are all considerably lower than at $25^{\circ}$ as might be expected; the average $r_{m}$ at $16^{\circ}$ is almost exactly one-half of that at $25^{\circ}$. More

TABLE 2

The mean values of $\mathrm{r}$, the " innate capacity for increase", variances, $\mathrm{s}_{\mathrm{r}}^{2}$, and their degrees of freedom for the populations studied

\begin{tabular}{|c|c|c|c|c|c|c|}
\hline \multirow{2}{*}{ Population } & \multirow{2}{*}{ Chromosomes } & & \multicolumn{2}{|c|}{$25^{\circ}$} & \multicolumn{2}{|c|}{$16^{\circ}$} \\
\hline & & & $196 I$ & I 962 & I96I & I 962 \\
\hline $2 I I$ & $\mathrm{AR}+\mathrm{CH}$ & $\begin{array}{l}\bar{r} \\
s_{r}^{2} \\
\text { d.f. }\end{array}$ & $\begin{array}{c}0 \cdot 217 \\
0 \cdot 000116 \text { I } \\
26\end{array}$ & $\begin{array}{c}0 \cdot 222 \\
0 \cdot 0005^{8} 19 \\
36\end{array}$ & $\begin{array}{c}0 \cdot 104 \\
0 \cdot 0000586 \\
26\end{array}$ & $\begin{array}{c}0 \cdot 096 \\
0 \cdot 000044^{2} \\
36\end{array}$ \\
\hline 212 & $\mathrm{AR}$ & $\begin{array}{l}\bar{r} \\
s_{r}^{2} \\
\text { d.f. }\end{array}$ & $\begin{array}{c}0 \cdot 19^{8} \\
0 \cdot 0002430 \\
26\end{array}$ & $\begin{array}{c}0.215 \\
0.0007639 \\
3^{6}\end{array}$ & $\begin{array}{c}0.097 \\
0.0000690 \\
26\end{array}$ & $\begin{array}{c}0.098 \\
0.0000765 \\
36\end{array}$ \\
\hline 213 & $\mathrm{CH}$ & $\begin{array}{l}\bar{r} \\
s_{r}^{2} \\
\text { d.f. }\end{array}$ & $\begin{array}{c}0 \cdot 200 \\
0 \cdot 0003579 \\
26\end{array}$ & $\begin{array}{c}0 \cdot 185 \\
0 \cdot 0005056 \\
36\end{array}$ & $\begin{array}{c}0 \cdot 101 \\
0 \cdot 0000247 \\
25\end{array}$ & $\begin{array}{c}0.091 \\
0.000043^{1} 8 \\
36\end{array}$ \\
\hline 183 & $\mathrm{AR}+\mathrm{PP}$ & $\begin{array}{l}\bar{r} \\
s_{r}^{2} \\
\text { d.f. }\end{array}$ & $\begin{array}{c}0.226 \\
0.0004959 \\
26\end{array}$ & $\begin{array}{c}0.226 \\
0 \cdot 0002234 \\
35\end{array}$ & $\begin{array}{c}0 \cdot 120 \\
0.0000554 \\
26\end{array}$ & $\begin{array}{c}\text { O.II } 2 \\
\text { O.0000993 } \\
36\end{array}$ \\
\hline 204 & $\mathrm{AR}+\mathrm{PP}$ & $\begin{array}{l}\bar{r} \\
s_{r}^{2} \\
\text { d.f. }\end{array}$ & $\begin{array}{c}0 \cdot 209 \\
0 \cdot 0008084 \\
26\end{array}$ & $\begin{array}{c}0 \cdot 210 \\
0.0004043 \\
36\end{array}$ & $\begin{array}{c}0 \cdot 106 \\
0 \cdot 0001543 \\
26\end{array}$ & $\begin{array}{c}0 \cdot 108 \\
0 \cdot 0000545 \\
36\end{array}$ \\
\hline 207 & $\mathrm{AR}+\mathrm{PP}$ & $\begin{array}{l}\bar{r} \\
s_{r}^{2} \\
\text { d.f. }\end{array}$ & $\begin{array}{c}0 \cdot 196 \\
0 \cdot 0008984 \\
26\end{array}$ & $\begin{array}{c}0 \cdot 220 \\
0 \cdot 0002 \text { 1 } 86 \\
36\end{array}$ & $\begin{array}{c}0.093 \\
0.0002066 \\
26\end{array}$ & $\begin{array}{c}0 \cdot 122 \\
0 \cdot 0000722 \\
36\end{array}$ \\
\hline 206 & $\mathrm{AR}$ & $\begin{array}{l}\bar{r} \\
s_{r}^{2} \\
\text { d.f. }\end{array}$ & $\begin{array}{c}0.205 \\
0 \cdot 00075^{12} \\
26\end{array}$ & $\begin{array}{c}0 \cdot 197 \\
0 \cdot 0007953 \\
36\end{array}$ & $\begin{array}{c}0.114 \\
0 \cdot 0000537 \\
26\end{array}$ & $\begin{array}{c}0 \cdot 108 \\
0 \cdot 0001365 \\
36\end{array}$ \\
\hline 209 & AR & $\begin{array}{l}\bar{r} \\
s_{r}^{2} \\
\text { d.f. }\end{array}$ & $\begin{array}{c}0 \cdot 198 \\
0 \cdot 0007670 \\
27\end{array}$ & $\begin{array}{c}0 \cdot 220 \\
0 \cdot 000238 \mathrm{I} \\
36\end{array}$ & $\begin{array}{c}0 \cdot 102 \\
0 \cdot 0002275 \\
27\end{array}$ & $\begin{array}{c}0 \cdot 106 \\
0 \cdot 0001333 \\
36\end{array}$ \\
\hline 205 & PP & $\begin{array}{l}\bar{r} \\
s_{r}^{2} \\
\text { d.f. }\end{array}$ & $\begin{array}{c}0 \cdot 158 \\
0 \cdot 0007067 \\
26\end{array}$ & $\begin{array}{c}0 \cdot 177 \\
0 \cdot 0006_{3} 12 \\
36\end{array}$ & $\begin{array}{c}0.090 \\
0.0002694 \\
26\end{array}$ & $\begin{array}{c}0 \cdot 09^{8} \\
0 \cdot 000073^{6} \\
36\end{array}$ \\
\hline 208 & PP & $\begin{array}{l}\tilde{r} \\
s_{r}^{2} \\
\text { d.f. }\end{array}$ & $\begin{array}{c}0 \cdot 149 \\
0 \cdot 0052889 \\
26\end{array}$ & $\begin{array}{c}0 \cdot 197 \\
0 \cdot 000554^{8} \\
36\end{array}$ & $\begin{array}{c}0 \cdot 087 \\
0 \cdot 000468 \mathrm{I} \\
26\end{array}$ & $\begin{array}{c}0 \cdot 104 \\
0 \cdot 0001429 \\
36\end{array}$ \\
\hline
\end{tabular}

important and interesting is the difference between genotypes. It is immediately obvious that at both temperatures the polymorphic populations and the pure $\mathrm{AR}$ populations have the highest $r_{m}$; pure 
PP populations have the lowest and pure $\mathrm{CH}$ populations are intermediate. This can be seen better in table 3, where the genotypes are arranged in descending order. In these tabulations the replicate populations of $\mathrm{AR}+\mathrm{PP}, \mathrm{AR}$ and $\mathrm{PP}$ have been averaged together

TABLE 3

Ordered comparisons of rates of increases, $\mathrm{r}_{\mathrm{m}}$, for different genotypes. Order is based on averages over the two years

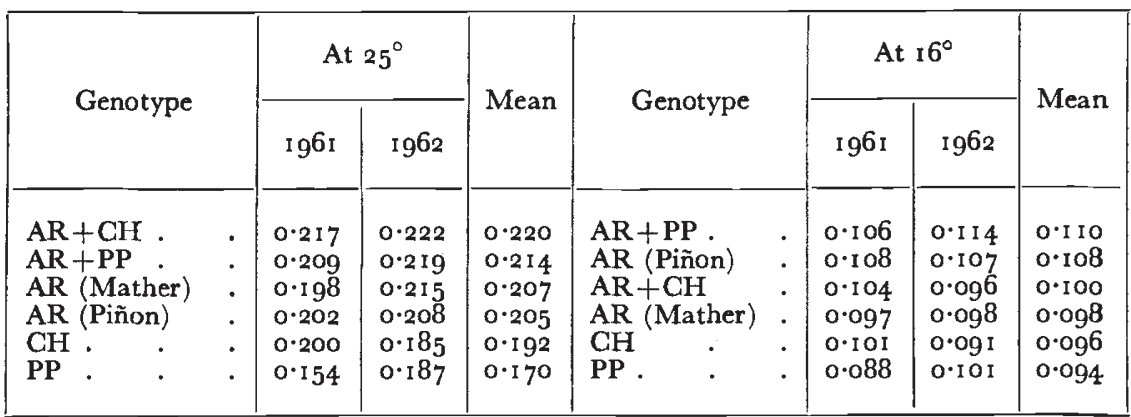

although population $212 \mathrm{AR}$ is not pooled together with the other two AR populations since it is of a different geographical origin. At $25^{\circ}$ the polymorphic populations are higher than the monomorphic populations, and among the monomorphics $\mathrm{AR}$ is best, $\mathrm{CH}$ next and

TABLE 4

Analysis of variance for the data in table 3

\begin{tabular}{|c|c|c|c|c|c|c|c|c|}
\hline \multirow{2}{*}{ Source } & \multicolumn{2}{|c|}{ At $25^{\circ}$} & \multirow{2}{*}{ M.S. } & \multirow{2}{*}{ F } & \multicolumn{2}{|c|}{ At $16^{\circ}$} & \multirow{2}{*}{ M.S. } & \multirow{2}{*}{$\mathbf{F}$} \\
\hline & S.S. & d.f. & & & S.S. & d.f. & & \\
\hline Years & 0.013065 & I & 0.013065 & I 7.3 & 0.000004 & I & 0.000004 & 0.025 \\
\hline Genotypes & O.I 55935 & 5 & 0.031187 & $\begin{array}{c}P<0.001 \\
4 \mathrm{I} \cdot 4 \\
P<0.001\end{array}$ & 0.020370 & 5 & 0.004074 & $\begin{array}{c}P>0.9 \\
26.8 \\
P<0.001\end{array}$ \\
\hline Interaction & $0.03^{1035}$ & 5 & 0.006207 & $\begin{array}{c}8 \cdot 2 \\
\mathrm{P}<0 \cdot 001\end{array}$ & $0.00995^{\circ}$ & 5 & 0.001990 & $\begin{array}{c}13.1 \\
P<0.001\end{array}$ \\
\hline Error & 0.474448 & $63^{\circ}$ & 0.000754 & & 0.096006 & 629 & 0.000152 & \\
\hline
\end{tabular}

PP poorest. There is no appreciable difference between the Arrowhead populations of different geographical origin.

At $16^{\circ}$ the picture is less clear. The differences among the genotypes are not as great, and while $\mathrm{CH}$ and PP monomorphic populations are still the poorest, there is no consistent superiority of polymorphic populations over monomorphic Arrowhead.

Before any discussion of the biological significance of these differences is possible, it is necessary to test whether the differences among the genotypes are in fact real. Table 4 shows the results of 
two separate analyses of variance, one for each temperature, of the data in table 3. The within genotype sum of squares has been obtained by combining the within population variances given in table 2 with the between population variances where there is more than one population of a given genotype. The total sum of squares thus obtained is divided by the total of all the degrees of freedom in table 2, plus the extra degrees of freedom introduced from replicate populations. Since different numbers of degrees of freedom are involved for the within genotype variances in different populations, the harmonic mean of the different numbers is used in the analysis. The tests of main effects and interactions use the error mean square since the model is a fixed factor design.

The analysis of variance shows that the genotypes differ significantly from each other at both temperatures; at $25^{\circ}$, but not at $16^{\circ}$, there is a difference between years, the value of $r_{m}$ having increased with the life of the populations.

\section{THE COMPONENTS OF $r_{m}$}

Before discussing the differences in the various components of $r_{m}$, the relationship of the components to $r_{m}$ itself needs to be considered.

TABLE 5

Number of eggs per female per life

\begin{tabular}{|c|c|c|c|c|c|}
\hline \multirow{2}{*}{ Population } & \multirow{2}{*}{ Chromosomes } & \multicolumn{2}{|c|}{ Eggs at $25^{\circ} \mathrm{C}$. } & \multicolumn{2}{|c|}{ Eggs at $16^{\circ} \mathrm{C}$. } \\
\hline & & $196 \mathrm{I}$ & 1962 & $196 \mathrm{I}$ & 1962 \\
\hline $\begin{array}{l}211 \\
212 \\
213 \\
183 \\
204 \\
207 \\
206 \\
209 \\
205 \\
208\end{array}$ & $\begin{array}{c}\mathrm{AR}+\mathrm{CH} \\
\mathrm{AR} \\
\mathrm{CH} \\
\mathrm{AR}+\mathrm{PP} \\
\mathrm{AR}+\mathrm{PP} \\
\mathrm{AR}+\mathrm{PP} \\
\mathrm{AR} \\
\mathrm{AR} \\
\mathrm{PP} \\
\mathrm{PP}\end{array}$ & $\begin{array}{r}431 \cdot 3 \\
282 \cdot 9 \\
316 \cdot 4 \\
248 \cdot 2 \\
202 \cdot 4 \\
218 \cdot 2 \\
334 \cdot 7 \\
215 \cdot 1 \\
81 \cdot 5 \\
82 \cdot 3\end{array}$ & $\begin{array}{l}322 \cdot 7 \\
239 \cdot 6 \\
182 \cdot 1 \\
276 \cdot 2 \\
285 \cdot 6 \\
275 \cdot 8 \\
176 \cdot 5 \\
334 \cdot 1 \\
140 \cdot 9 \\
168 \cdot 7\end{array}$ & $\begin{array}{l}374 \cdot 0 \\
307 \cdot 5 \\
319 \cdot 9 \\
418 \cdot 1 \\
315 \cdot 6 \\
333 \cdot 6 \\
401 \cdot 6 \\
273 \cdot 4 \\
238 \cdot 6 \\
206 \cdot 7\end{array}$ & $\begin{array}{l}629 \cdot 5 \\
524 \cdot 6 \\
420 \cdot 0 \\
744 \cdot 4 \\
622 \cdot 4 \\
725 \cdot 3 \\
531 \cdot 6 \\
56 \cdot \cdot 8 \\
428 \cdot 6 \\
472 \cdot 9\end{array}$ \\
\hline
\end{tabular}

In general, an increase in total fecundity, or average longevity will increase $r_{m}$ but not in any simple way. Equation (3) shows that the contribution of eggs laid at time $x$ to $r_{m}$ is proportional to $e^{-r x}$. Thus, eggs laid late in life make very little contribution. For example, if $r_{m}=0.25$, each egg laid on day I makes a contribution to the summation in equation (3) of 0.78 , while each egg on the roth day makes a contribution of only 0.08 . The same is true for added longevity. In addition, small decreases in development time (F) count heavily in increasing $r$. In our data, for example, a I-day decrease in development time has the same effect as increasing the egg laying rate or larval viability by one-third. For this reason, mean fecundities or mean 
longevities are not really good indices of population performance. This is shown clearly in our data. Taking total lifetime fecundities (table 5), the order of populations at $25^{\circ}$ is:

$$
\mathrm{AR}+\mathrm{CH} \gg \mathrm{AR} \text { (Mather) }>\mathrm{AR} \text { (Piñon) }>\mathrm{AR}+\mathrm{PP}=\mathrm{CH} \gg \mathrm{PP}
$$

which does not correspond to the ordering of $r_{m}$ values in table 2. If only the fecundities during the first Io days of egg laying are taken (table 6), the order is:

$$
\mathrm{AR}+\mathrm{CH}>\mathrm{AR}+\mathrm{PP}>\mathrm{AR} \text { (Mather) }=\mathrm{AR} \text { (Piñon) }>\mathrm{CH}>\mathrm{PP}
$$

which is in excellent agreement with the ordering of $r_{m}$ values in table 2.

TABLE 6

\begin{tabular}{|c|c|c|c|c|c|}
\hline \multicolumn{2}{|c|}{ Population } & \multirow{2}{*}{ Year } & \multicolumn{3}{|c|}{ Interval (days) } \\
\hline & & & $3-6$ & $7-12$ & $13+$ \\
\hline 211 & $\mathrm{AR}+\mathrm{CH}$ & $196 \mathrm{I}$ & $18 \cdot 1 \pm 2 \cdot 2$ & $18 \cdot 2 \pm 1 \cdot 9$ & $6 \cdot 2 \pm 0 \cdot 9$ \\
\hline 212 & AR & $196 \mathrm{I}$ & $33.3 \pm 1 \cdot 7$ & $I I \cdot I \pm I \cdot I$ & $2 \cdot 3 \pm 0 \cdot 4$ \\
\hline 213 & $\mathrm{CH}$ & $196 \mathrm{I}$ & $16.7 \pm 1.7$ & II.8士I.2 & $4.6 \pm 0.7$ \\
\hline 211 & $\mathrm{AR}+\mathrm{CH}$ & 1962 & $25 \cdot 9 \pm 2 \cdot 6$ & $12.2 \pm 1.0$ & $4.6 \pm 0.5$ \\
\hline 212 & AR & 1962 & $23 \cdot 3 \pm 2 \cdot 3$ & $15.6 \pm 1 \cdot 4$ & $5 \cdot 0 \pm 1 \cdot 0$ \\
\hline 213 & $\mathrm{CH}$ & 1962 & $13.8 \pm 1.1$ & $7 \cdot 3 \pm 0.8$ & $2.5 \pm 0.5$ \\
\hline $\begin{array}{l}183 \\
\end{array}$ & $\mathrm{AR}+\mathrm{PP}$ & $196 \mathrm{I}$ & $20 \cdot 0 \pm 1 \cdot 6$ & $12.8 \pm 1.6$ & $5 \cdot 5 \pm 1 \cdot 4$ \\
\hline 204 & $\mathrm{AR}+\mathbf{P P}$ & $196 \mathrm{I}$ & $17 \cdot 6 \pm 1 \cdot 5$ & $9 \cdot 7 \pm 1 \cdot 3$ & $4 \cdot 0 \pm 0.7$ \\
\hline 207 & $\mathrm{AR}+\mathrm{PP}$ & $196 \mathrm{I}$ & $17.6 \pm 1.5$ & $10.3 \pm 1.8$ & $5 \cdot 7 \pm 1 \cdot 0$ \\
\hline 206 & $\mathrm{AR}$ & $196 \mathrm{I}$ & $20 \cdot 8 \pm 1 \cdot 2$ & I1. $1 \pm 0.5$ & $5 \cdot 1 \pm 0 \cdot 7$ \\
\hline 209 & $\mathrm{AR}$ & $196 \mathrm{I}$ & $13.9 \pm 1 \cdot 3$ & $8 \cdot 8 \pm 1 \cdot 1$ & $6.6 \pm 0.8$ \\
\hline 205 & PP & 1961 & $8 \cdot 3 \pm 1 \cdot 5$ & $5.1 \pm 0.9$ & $5.2 \pm 0.9$ \\
\hline 208 & PP & 1961 & $9 \cdot 5 \pm 1 \cdot I$ & $2 \cdot 0 \pm 0 \cdot 6$ & $0=0$ \\
\hline 183 & $\mathrm{AR}+\mathrm{PP}$ & 1962 & $22 \cdot 3 \pm 1 \cdot 3$ & $9 \cdot 4 \pm 1 \cdot 0$ & $2 \cdot 4 \pm 0 \cdot 6$ \\
\hline 204 & $\mathrm{AR}+\mathrm{PP}$ & 1962 & $19 \cdot 1 \pm 1 \cdot 7$ & $12 \cdot 2 \pm 1 \cdot 3$ & $3 \cdot 8 \pm 0 \cdot 7$ \\
\hline 207 & $\mathrm{AR}+\mathrm{PP}$ & 1962 & $19.7 \pm 1.5$ & $12.2 \pm 1.0$ & $3.4 \pm 0.5$ \\
\hline 206 & $\mathrm{AR}$ & 1962 & $17 \cdot 3 \pm 1.6$ & $9 \cdot 3 \pm 1 \cdot 2$ & $2 \cdot 6 \pm 0.8$ \\
\hline 209 & $\mathrm{AR}$ & 1962 & $20 \cdot 6 \pm 1 \cdot 3$ & $16.5 \pm 0.8$ & $4 \cdot 4 \pm 0 \cdot 6$ \\
\hline 205 & PP & 1962 & $12.4 \pm 1.0$ & $5 \cdot 5 \pm 0.6$ & $1.4 \pm 0.3$ \\
\hline 208 & PP & 1962 & $15.0 \pm 1.3$ & $8 \cdot 9 \pm 1 \cdot 2$ & $0.6 \pm 0.5$ \\
\hline
\end{tabular}

Mean number of eggs per female per day at $25^{\circ}$

Such a consideration may, in fact, lie at the basis of discrepancies between intra-population fitness and fitness as measured by $r_{m}$.

The variables which make little contribution to $r_{m}$ may nevertheless be important in population fitness. It is, for example, conceivable that under some environmental conditions it is the fecundity of the most long-lived I per cent. of the population that enables the population to survive instead of becoming extinct. We have, therefore, examined the components of $r_{m}$ in detail.

\section{FECUNDITY}

Cups were taken from the population cages when pupæ were forming in them, provided with transparent plastic "chimneys", and the flies were collected daily when they hatched. Groups of 4 females 
and equal or greater numbers of males were placed in glass tubes with cotton plugs, and given paper spoons with a nutrient medium for oviposition. The medium devised by Kalmus, to which carbon black was added to make the eggs more conspicuous, was used, its surface being lightly smeared with a suspension of Fleishmann's yeast. The eggs were counted, and spoons with fresh medium were substituted daily at $25^{\circ}$, and on alternate days at $16^{\circ} \mathrm{C}$.

The mean lifetime egg production per female is reported in table 5 . The fecundity in our experiments was much lower than that observed by Tantawy and Vetukhiv (1960) and Tantawy (1961). The difference is due to the techniques used. In our experiments, the ovipositing females were raised in overcrowded cups in the population cages, while in those of the authors just quoted they were raised under more nearly optimal conditions. This was planned deliberately, to observe the capacity for increase in populations developed under crowding and competition for food, when this competition is suddenly removed. Moreover, the Kalmus medium seems to be less favourable for oviposition than the regular Spassky culture medium used in our laboratory. It must, then, be stressed that the $r_{m}$ values which we have obtained are certainly not the maximal which the species is capable of developing.

The population No. 2II, polymorphic for AR and CH, showed a higher total fecundity than the monomorphic AR or $\mathrm{CH}$ (Nos. 212 and 213). The monomorphic PP populations are consistently below the monomorphic $\mathrm{AR}$ or the polymorphic $\mathrm{AR}+\mathrm{PP}$, but the latter give variable and inconsistent results. At $25^{\circ}$, AR No. 206 had the highest fecundity in $19^{6} 1$ and one of the lowest in 1962, while AR No. 209 was most fecund in 1962 but only moderately so in $196 \mathrm{I}$. In general, the flies were more fecund in 1962 than in 1961 (in 16 out of the 20 paired comparisons listed in table 5). There were, however, some exceptions, the two most striking ones being populations Nos. 2 I 3 and 206 at $25^{\circ}$. Several generations in a population cage lead to an "improvement" in that environment.

In Drosophila pseudoobscura, the oviposition starts within a few days after the hatching from the pupa, rapidly increases to a maximum and then declines slowly until death. We have made daily counts of the eggs at $25^{\circ}$, and on alternate days at $16^{\circ}$. The numbers of eggs deposited by a female on successive days are highly variable. It appears that a crop of eggs mature in the ovaries, are deposited within a few hours and then it takes a day or two for a new crop of eggs to be ready for deposition. For statistical purposes, we have rather arbitrarily divided the oviposition period in three parts at $25^{\circ}$, and in five parts at $16^{\circ}$, and then computed the mean numbers of eggs per day deposited by a female in the ten replicate cultures of each population (each containing initially 4 females and about 6 males). The first two days of life at $25^{\circ}$, and the first three at $16^{\circ}$, are disregarded, since very few eggs are produced by immature females. 
Although the experimental errors are large, it is clear enough that the females from the polymorphic populations tend to be more fecund at $25^{\circ}$ than those from the monomorphic ones (table 6), especially during the early part of the oviposition period. The AR $+\mathrm{CH}$ population produced more eggs than $\mathrm{AR}$ or $\mathrm{CH}$; the $\mathrm{AR}+\mathrm{PP}$ populations were clearly more fecund than PP, but about equal to AR. At $16^{\circ}$ (table 7) the situation is less clear. The polymorphic $\mathrm{AR}+\mathrm{CH}$ was

TABLE 7

Mean number of eggs per female per day at $16^{\circ}$

\begin{tabular}{|c|c|c|c|c|c|c|c|}
\hline \multirow{2}{*}{\multicolumn{2}{|c|}{ Population }} & \multirow{2}{*}{$\begin{array}{l}\text { Year } \\
\text { I } 66 \mathrm{I}\end{array}$} & \multicolumn{5}{|c|}{ Interval (days) } \\
\hline & & & $4^{-6}$ & $7-12$ & $13-24$ & $25-36$ & $37+$ \\
\hline $\begin{array}{l}211 \\
212 \\
213\end{array}$ & $\begin{array}{c}\mathrm{AR}+\mathrm{CH} \\
\mathrm{AR} \\
\mathrm{CH}\end{array}$ & $\begin{array}{l}196 \mathrm{I} \\
196 \mathrm{I} \\
196 \mathrm{I}\end{array}$ & $\begin{array}{r}10 \cdot 3 \pm 2 \cdot 9 \\
7 \cdot 6 \pm 1 \cdot 5 \\
10 \cdot 4 \pm 1 \cdot 4\end{array}$ & $\begin{array}{r}10 \cdot 6 \pm 1 \cdot 0 \\
8 \cdot 3 \pm 1 \cdot 3 \\
8 \cdot 9 \pm 0 \cdot 9\end{array}$ & $\begin{array}{l}6 \cdot 7 \pm 0.7 \\
4 \cdot 3 \pm 0.6 \\
4 \cdot 9 \pm 0.4\end{array}$ & $\begin{array}{l}4 \cdot 2 \pm 0 \cdot 6 \\
2 \cdot 8 \pm 0 \cdot 4 \\
2 \cdot 2 \pm 0 \cdot 3\end{array}$ & $\begin{array}{l}3.1 \pm 0.4 \\
3.1 \pm 0.6 \\
1.0 \pm 0.2\end{array}$ \\
\hline $\begin{array}{l}211 \\
212 \\
213\end{array}$ & $\begin{array}{c}\mathrm{AR}+\mathrm{CH} \\
\mathrm{AR} \\
\mathrm{CH}\end{array}$ & $\begin{array}{l}1962 \\
1962 \\
1962\end{array}$ & $\begin{array}{r}11 \cdot 8 \pm 1 \cdot 9 \\
10 \cdot 2 \pm 1 \cdot 3 \\
8 \cdot 4 \pm 1 \cdot 3\end{array}$ & $\begin{array}{l}17.1 \pm 0.9 \\
14.5 \pm 1 \cdot 0 \\
11.8 \pm 0.8\end{array}$ & $\begin{array}{l}13.6 \pm 0.7 \\
10.6 \pm 0.7 \\
\text { 10.6士0.6 }\end{array}$ & $\begin{array}{l}8 \cdot 1 \pm 0.9 \\
6 \cdot 1 \pm 0.6 \\
4.5 \pm 0.5\end{array}$ & $\begin{array}{l}8 \cdot 2 \pm 1 \cdot 3 \\
4 \cdot 1 \pm 0 \cdot 5 \\
1 \cdot 7 \pm 0 \cdot 3\end{array}$ \\
\hline $\begin{array}{l}183 \\
204 \\
207 \\
206 \\
209 \\
205 \\
208\end{array}$ & $\begin{array}{c}\mathrm{AR}+\mathrm{PP} \\
\mathrm{AR}+\mathrm{PP} \\
\mathrm{AR}+\mathrm{PP} \\
\mathrm{AR} \\
\mathrm{AR} \\
\mathrm{PP} \\
\mathrm{AR}\end{array}$ & $\begin{array}{l}1961 \\
1961 \\
1961 \\
1961 \\
1961 \\
1961 \\
1961\end{array}$ & $\begin{array}{r}I 1 \cdot 3 \pm 1 \cdot 0 \\
I 1 \cdot 3 \pm 1 \cdot 2 \\
9 \cdot 5 \pm 1 \cdot 2 \\
13 \cdot 5 \pm 1 \cdot 0 \\
8 \cdot 5 \pm 1 \cdot 1 \\
4 \cdot 7 \pm 0 \cdot 8 \\
7 \cdot 9 \pm 1 \cdot 4\end{array}$ & $\begin{array}{r}13.3 \pm 1.2 \\
9.5 \pm 0.9 \\
8.0 \pm 0.9 \\
7.5 \pm 0.7 \\
5.1 \pm 0.7 \\
6.1 \pm 0.7 \\
5.1 \pm 0.7\end{array}$ & $\begin{array}{l}8.4 \pm 0.7 \\
7.8 \pm 1 \cdot 0 \\
5.9 \pm 0.5 \\
7.8 \pm 0.6 \\
7.8 \pm 0.4 \\
7.6 \pm 0.7 \\
9.7 \pm 0.9\end{array}$ & $\begin{array}{l}5.3 \pm 0.6 \\
5.1 \pm 0.8 \\
1.4 \pm 0.3 \\
5.6 \pm 0.6 \\
3.2 \pm 0.6 \\
3.53 \pm 0.5 \\
5.6 \pm 0.6\end{array}$ & $\begin{array}{c}1 \cdot 6 \pm 0.5 \\
0.5 \pm 0.2 \\
1 \cdot 1 \pm 0.3 \\
1 \cdot 3 \pm 0.4 \\
= \\
0 \\
1 \cdot 3 \pm 0.4\end{array}$ \\
\hline $\begin{array}{l}183 \\
204 \\
207 \\
206 \\
209 \\
205 \\
208\end{array}$ & $\begin{array}{c}\mathrm{AR}+\mathrm{PP} \\
\mathrm{AR}+\mathrm{PP} \\
\mathrm{AR}+\mathrm{PP} \\
\mathrm{AR} \\
\mathrm{AR} \\
\mathrm{PP} \\
\mathrm{PP}\end{array}$ & $\begin{array}{l}1962 \\
1962 \\
1962 \\
1962 \\
1962 \\
1962 \\
1962\end{array}$ & $\begin{array}{l}14 \cdot 0 \pm 1 \cdot 3 \\
14.9 \pm 1 \cdot 5 \\
15 \cdot 8 \pm 1 \cdot 2 \\
13.4 \pm 1 \cdot 4 \\
10 \cdot 1 \pm 1 \cdot 2 \\
12 \cdot 1 \pm 1 \cdot 2 \\
12 \cdot 6 \pm 1 \cdot 2\end{array}$ & $\begin{array}{l}17.5 \pm 1.1 \\
17.1 \pm 1.2 \\
18.0 \pm 1.3 \\
14.1 \pm 0.9 \\
13.2 \pm 0.8 \\
12.2 \pm 0.7 \\
12.6 \pm 0.8\end{array}$ & 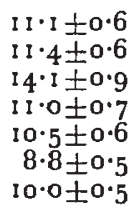 & $\begin{array}{l}7.8 \pm 0.7 \\
5.6 \pm 0.6 \\
7.7 \pm 0.7 \\
8.0 \pm 0.6 \\
6.8 \pm 0.5 \\
4.3 \pm 0.4 \\
5.2 \pm 0.5\end{array}$ & $\begin{array}{l}6.5 \pm 0.8 \\
4.3 \pm 0.6 \\
4 \cdot 0 \pm 0.8 \\
2 \cdot 4 \pm 0.3 \\
2 \cdot 8 \pm 0.3 \\
0.9 \pm 0.8 \\
1 \cdot 2 \pm 0.9\end{array}$ \\
\hline
\end{tabular}

rather consistently above $\mathrm{AR}$ or $\mathrm{CH}$ in 1962 , but not in $\mathrm{r} 96 \mathrm{r}$. Among the polymorphic AR + PP, the population No. 207 was below the other two (Nos. 183 and 204) in 1961, but above in 1962 . The monomorphic PP tended to be low in fecundity, but not consistently so. At $16^{\circ}$, the fecundity was quite consistently higher in 1962 than in 1961, while at $25^{\circ}$ it was sometimes higher and sometimes lower. An "improvement" at the lower temperature was actually unexpected, because the populations from which the material came were kept at the higher temperature, $25^{\circ}$.

\section{LONGEVITY}

The flies for measurements of the longevity were obtained from the same source as those used in the fecundity tests, i.e., from the cups withdrawn from the population cages. However, to study the longevity 
groups of Io females and ro males were placed in half-pint bottles with Kalmus medium to which no carbon black was added. A drop of yeast suspension and a loose strip of sterilised white paper towelling were placed in each bottle. For each population, io replicate bottles were kept at $25^{\circ}$ and an equal number at $16^{\circ}$. The flies were transferred, without etherisation, to fresh culture bottles at 2-day intervals

TABLE 8

Mean longevity, in days, in females and in males

\begin{tabular}{|c|c|c|c|c|c|}
\hline \multirow{2}{*}{ Population } & \multirow{2}{*}{ Chromosomes } & \multicolumn{2}{|c|}{$25^{\circ}$} & \multicolumn{2}{|c|}{$16^{\circ}$} \\
\hline & & I 96 I & 1962 & I 96 I & I 962 \\
\hline \multicolumn{6}{|c|}{ Females } \\
\hline $\begin{array}{l}211 \\
212 \\
213 \\
183 \\
204 \\
207 \\
206 \\
209 \\
205 \\
208\end{array}$ & $\begin{array}{c}\mathrm{AR}+\mathrm{CH} \\
\mathrm{AR} \\
\mathrm{CH} \\
\mathrm{AR}+\mathrm{PP} \\
\mathrm{AR}+\mathrm{PP} \\
\mathrm{AR}+\mathrm{PP} \\
\mathrm{AR} \\
\mathrm{AR} \\
\mathrm{PP} \\
\mathrm{PP}\end{array}$ & $\begin{array}{l}38 \cdot 09 \pm \mathrm{I} \cdot 2 \mathrm{I} \\
37 \cdot 5 \mathrm{I} \pm \mathrm{I} \cdot 24 \\
3 \mathrm{I} \cdot 28 \pm \mathrm{I} \cdot 10 \\
26 \cdot 09 \pm \mathrm{I} \cdot 03 \\
26 \cdot 96 \pm \mathrm{I} \cdot 20 \\
26 \cdot 02 \pm 0 \cdot 97 \\
38 \cdot 10 \pm \mathrm{I} \cdot 57 \\
29 \cdot 36 \pm \mathrm{I} \cdot 5 \mathrm{I} \\
18 \cdot 89 \pm 0 \cdot 88 \\
15 \cdot 6 \mathrm{I} \pm 0 \cdot 82\end{array}$ & $\begin{array}{l}29 \cdot 09 \pm 0 \cdot 83 \\
25 \cdot 81 \pm 0 \cdot 86 \\
25 \cdot 08 \pm 0 \cdot 67 \\
27 \cdot 16 \pm 0 \cdot 78 \\
25 \cdot 83 \pm 0 \cdot 77 \\
24 \cdot 15 \pm 0 \cdot 71 \\
25 \cdot 47 \pm 0 \cdot 76 \\
25 \cdot 96 \pm 0 \cdot 77 \\
20 \cdot 05 \pm 0 \cdot 68 \\
24 \cdot 81 \pm 0 \cdot 73\end{array}$ & $\begin{array}{l}88 \cdot 55 \pm 3 \cdot 18 \\
89 \cdot 44 \pm 3 \cdot 56 \\
77 \cdot 27 \pm 2 \cdot 47 \\
66 \cdot 38 \pm 2 \cdot 75 \\
53 \cdot 55 \pm 2 \cdot 53 \\
40 \cdot 44 \pm 2 \cdot 68 \\
60 \cdot 37 \pm 2 \cdot 23 \\
68 \cdot 26 \pm 2 \cdot 70 \\
47 \cdot 78 \pm 2 \cdot 93 \\
33 \cdot 95 \pm 2 \cdot 01\end{array}$ & $\begin{array}{l}56 \cdot 09 \pm 1 \cdot 81 \\
62 \cdot 30 \pm 1 \cdot 95 \\
55 \cdot 45 \pm 1 \cdot 73 \\
55 \cdot 05 \pm 1 \cdot 54 \\
53 \cdot 38 \pm 1 \cdot 27 \\
54 \cdot 44 \pm 1 \cdot 37 \\
47 \cdot 74 \pm 1 \cdot 38 \\
49 \cdot 29 \pm 1 \cdot 20 \\
48 \cdot 84 \pm I \cdot 61 \\
48 \cdot 29 \pm I \cdot 27\end{array}$ \\
\hline \multicolumn{6}{|c|}{ Males } \\
\hline $\begin{array}{l}211 \\
212 \\
213 \\
183 \\
204 \\
207 \\
206 \\
209 \\
205 \\
208\end{array}$ & $\begin{array}{c}\mathrm{AR}+\mathrm{CH} \\
\mathrm{AR} \\
\mathrm{CH} \\
\mathrm{AR}+\mathrm{PP} \\
\mathrm{AR}+\mathrm{PP} \\
\mathrm{AR}+\mathrm{PP} \\
\mathrm{AR} \\
\mathrm{AR} \\
\mathrm{PP} \\
\mathrm{PP}\end{array}$ & $\begin{array}{l}22 \cdot 65 \pm 0.88 \\
22 \cdot 90 \pm 1 \cdot 00 \\
21 \cdot 95 \pm 0.76 \\
17 \cdot 12 \pm 0.60 \\
17.37 \pm 0.71 \\
19.88 \pm 0.58 \\
19.91 \pm 0.60 \\
16.51 \pm 0.57 \\
14.85 \pm 0.58 \\
10.69 \pm 0.35\end{array}$ & $\begin{array}{l}\text { 1 } 6.35 \pm 0.44 \\
\text { 1 } 4.82 \pm 0.43 \\
14.98 \pm 0.31 \\
20.43 \pm 0.58 \\
\text { I } 9.26 \pm 0.59 \\
\text { 1 } 6.65 \pm 0.54 \\
\text { 1 } 7.20 \pm 0.56 \\
19.14 \pm 0.60 \\
13.74 \pm 0.47 \\
14.90 \pm 0.56\end{array}$ & $\begin{array}{l}53 \cdot 52 \pm 1 \cdot 75 \\
51 \cdot 96 \pm 2 \cdot 57 \\
44 \cdot 93 \pm 1 \cdot 50 \\
30 \cdot 52 \pm 0 \cdot 95 \\
30 \cdot 63 \pm 0 \cdot 96 \\
19 \cdot 91 \pm 0 \cdot 79 \\
33 \cdot 66 \pm 0 \cdot 98 \\
31 \cdot 23 \pm 1 \cdot 38 \\
26 \cdot 17 \pm 0 \cdot 91 \\
20 \cdot 32 \pm 0 \cdot 77\end{array}$ & $\begin{array}{l}27 \cdot 30 \pm 0 \cdot 92 \\
28 \cdot 86 \pm 0 \cdot 87 \\
26 \cdot 44 \pm 0 \cdot 76 \\
37 \cdot 03 \pm 1 \cdot 01 \\
28 \cdot 88 \pm 0 \cdot 76 \\
31 \cdot 03 \pm 0 \cdot 82 \\
30 \cdot 92 \pm 0 \cdot 75 \\
30 \cdot 09 \pm 0 \cdot 81 \\
24 \cdot 49 \pm 0 \cdot 74 \\
21 \cdot 94 \pm 0 \cdot 61\end{array}$ \\
\hline
\end{tabular}

at $25^{\circ}$, and twice per week at $16^{\circ}$. The remains of dead flies, easily visible on the transparent medium, were counted. The results are reported in table 8. Each mean value is, thus, based on observation of 100 flies.

The results were different in 1961 and in 1962 . In 1961 , the females from the monomorphic $\mathrm{CH}$ population (No. 213) had a significantly shorter life duration than those from the monomorphic AR (No. 2 I2) or from the polymorphic $\mathrm{AR}+\mathrm{CH}$ population (No. 2I I). The same was true of the males at $16^{\circ}$, but at $25^{\circ}$ there was no significant difference. The polymorphic and the monomorphic $A R$ populations did not differ in longevity. The monomorphic PP populations (Nos. 205 and 
208) were inferior in longevity to the corresponding monomorphic AR (Mather, Nos. 206 and 209), but there was no consistent difference between the latter and the polymorphic AR +PP. At $I 6^{\circ}$, the polymorphic population No. 207 showed actually the lowest longevity.

In 1962 , the longevity was more nearly uniform in all populations than it was in 1961 . At $25^{\circ}$, but not at $16^{\circ}$, the polymorphic $\mathrm{AR}+\mathrm{CH}$ was superior to the monomorphic AR (No. 212) and CH. Monomorphic $\mathrm{PP}$ was no longer consistently inferior to $\mathrm{AR}$ and to $\mathrm{AR}+\mathrm{PP}$ -the inferiority seemed to persist in males but not in females. The polymorphic AR + PP lived longer than the monomorphic AR and $\mathrm{PP}$ at $16^{\circ}$ but not at $25^{\circ}$, and even then only as females but not as males. The striking and unexpected change was, however, that the mean longevity actually decreased in 1962 as compared with 1961 in most populations. While, as we have seen above, these populations improved with time with respect to the fecundity, they rather deteriorated with respect to longevity. Only the monomorphic PP populations (Nos. 205 and 206), which had the lowest longevity in I96I, did not change or even improve in 1962 . This is the main reason why the longevity of all populations was more uniform in 1962 than in 1961 .

\section{VIABILITY AND DEVELOPMENT RATE}

Females developed in the population cages were allowed to oviposite on paper spoons with the Kalmus synthetic medium, to which carbon black was added for easier visibility. Samples of 50 eggs were taken and transferred, on excised blocks of food (so that the eggs themselves were not distributed), to bottles with the ordinary culture medium. Ten such samples were taken from each population in $196 \mathrm{I}$, and another ten in 1962 . The adult flies hatching from these samples were counted; the results are summarised in table 9. The egg to adult survival was between 71 and 96 per cent., with no consistent differences between the populations or between years.

Rather unexpected technical difficulties arose in the study of the length of the development from egg to adult. The flies hatched in the population cages were transferred at daily intervals to fresh culture bottles, to ensure that the females were active egg layers and did not have developing eggs in their vaginæ (as happens with females which withhold their eggs because of unfavourable conditions). When the females were near the peak of their egg laying, they were transferred several times to fresh culture bottles, at intervals no more than 3 hours at $25^{\circ}$ and at most 6 hours at $16^{\circ}$, to obtain cultures with eggs deposited at a known time. Always more than Io replicate cultures were obtained for each series, because only the cultures in which more than 25 but fewer than roo adult flies hatched were utilised, and those underpopulated and overpopulated were ignored. The counts of the hatching flies were made twice daily in the 1961 series, and once daily in 1962. As a rule, the hatching extended from about the 12th to the 
I 7 th day at $25^{\circ}$, and from the $25^{\text {th }}$ to the 38 th day after the egg laying at $16^{\circ}$. Despite all the precautions, there was some heterogeneity among the replicate cultures, some developing faster and others slower than the rest. No relation was found between the development

TABLE 9

Viability-per cent. survival from egg to adult

\begin{tabular}{|c|c|c|c|c|c|}
\hline \multirow{2}{*}{ Population } & \multirow{2}{*}{ Chromosomes } & \multicolumn{2}{|c|}{$25^{\circ} \mathrm{C}$. } & \multicolumn{2}{|c|}{$16^{\circ} \mathrm{C}$} \\
\hline & & 1961 & I 962 & $196 \mathrm{I}$ & 1962 \\
\hline $\begin{array}{l}211 \\
212 \\
213 \\
183 \\
204 \\
207 \\
206 \\
209 \\
205 \\
208\end{array}$ & $\begin{array}{c}\mathrm{AR}+\mathrm{CH} \\
\mathrm{AR} \\
\mathrm{CH} \\
\mathrm{AR}+\mathrm{PP} \\
\mathrm{AR}+\mathrm{PP} \\
\mathrm{AR}+\mathrm{PP} \\
\mathrm{AR} \\
\mathrm{AR} \\
\mathrm{PP} \\
\mathrm{PP}\end{array}$ & $\begin{array}{l}90 \cdot 6 \\
87 \cdot 2 \\
71 \cdot 6 \\
84 \cdot 8 \\
79 \cdot 2 \\
81 \cdot 2 \\
90 \cdot 0 \\
89 \cdot 2 \\
83 \cdot 2 \\
75 \cdot 2\end{array}$ & $\begin{array}{l}88 \cdot 4 \\
90 \cdot 8 \\
87 \cdot 2 \\
92 \cdot 1 \\
92 \cdot 4 \\
88 \cdot 3 \\
89 \cdot 4 \\
93 \cdot 3 \\
83 \cdot 3 \\
82 \cdot 9\end{array}$ & $\begin{array}{l}96 \cdot 2 \\
91 \cdot 6 \\
77 \cdot 6 \\
93 \cdot 6 \\
86 \cdot 8 \\
90 \cdot 0 \\
96 \cdot 0 \\
94 \cdot 8 \\
90 \cdot 0 \\
75 \cdot 3\end{array}$ & $\begin{array}{l}88 \cdot 0 \\
87 \cdot 2 \\
88 \cdot 6 \\
89 \cdot 8 \\
88 \cdot 8 \\
89 \cdot 0 \\
92 \cdot 4 \\
87 \cdot 6 \\
82 \cdot 0 \\
81 \cdot 8\end{array}$ \\
\hline
\end{tabular}

TABLE IO

Rate of development from egg to adult in days (females)

\begin{tabular}{|c|c|c|c|c|c|}
\hline \multirow{2}{*}{ Population } & \multirow{2}{*}{ Chromosomes } & \multicolumn{2}{|c|}{$25^{\circ}$} & \multicolumn{2}{|c|}{$16^{\circ}$} \\
\hline & & I $96 \mathrm{I}$ & 1962 & I 961 & I 962 \\
\hline $21 I$ & $\mathrm{AR}+\mathrm{CH}$ & $13.73 \pm 0.17$ & $14.52 \pm 0.34$ & $31 \cdot 56 \pm 1 \cdot 05$ & $38.90 \pm 0.89$ \\
\hline 212 & $\mathrm{AR}$ & $\begin{array}{l}13.85 \pm 0.27\end{array}$ & $14.89 \pm 0.22$ & $31 \cdot 35 \pm 1 \cdot 06$ & $36 \cdot 5 \mathrm{I} \pm 0 \cdot 62$ \\
\hline 213 & $\mathrm{CH}$ & $14.44 \pm 0.22$ & $14.23 \pm 0.39$ & $30.40 \pm 0.61$ & $37 \cdot 02 \pm 1 \cdot 03$ \\
\hline 183 & $\mathrm{AR}+\mathrm{PP}$ & $13.74 \pm 0.17$ & $13.94 \pm 0.24$ & $29 \cdot 68 \pm 0 \cdot 39$ & $34.47 \pm 0.79$ \\
\hline 204 & $\mathrm{AR}+\mathrm{PP}$ & $13.72 \pm 0.26$ & $14 \cdot 16 \pm 0.22$ & $29 \cdot 34 \pm 0 \cdot 70$ & $33 \cdot 39 \pm 0 \cdot 4^{2}$ \\
\hline 207 & $\mathbf{A R} \pm \mathbf{P P}$ & $13.37 \pm 0.17$ & $13.51 \pm 0.22$ & $31.29 \pm 0.86$ & $30.72 \pm 0.51$ \\
\hline 206 & $\overline{A \bar{R}}$ & $13.40 \pm 0.17$ & $16 \cdot 46 \pm 0 \cdot 35$ & $3^{0.81} \pm 0.84$ & $33 \cdot 02 \pm 0.74$ \\
\hline 209 & $\mathrm{AR}$ & $13.66 \pm 0.16$ & $13.93 \pm 0.36$ & $30 \cdot 31 \pm 1 \cdot 41$ & $39.73 \pm 0.69$ \\
\hline 205 & PP & $13 \cdot 79 \pm 0 \cdot 45$ & $14 \cdot 32 \pm 0 \cdot 23$ & $28.22 \pm 0.55$ & $32.91 \pm 0.94$ \\
\hline 208 & PP & $13.50 \pm 0.09$ & $\begin{array}{l}13.50 \pm 0.27\end{array}$ & $3^{1 \cdot 5^{0} \pm I \cdot I I}$ & $37.01 \pm 0.53$ \\
\hline
\end{tabular}

time and the number of the flies hatching in a culture. None of the cultures utilised was overcrowded. We suspected that there may be temperature variations between the cultures standing on the front part and in the rear of the shelves in the constant temperature room. The whole experiment was repeated in 1961 , the cultures being moved daily from the front to the rear on the shelves, and vice versa. The heterogeneity between the replicating did not disappear. Evidently there were some environmental variations between the replicate cultures which we did not succeed in detecting and eliminating. 
As table 10 shows, the standard errors for development time are quite large, sometimes as great as I day, because of the relatively large differences between replicates. Thus, the observed differences between mean development times for the different populations cannot be given any significant biological interpretation.

\section{DISCUSSION}

Beardmore, Dobzhansky and Pavlovsky (1960), Dobzhansky and Pavlovsky (I96I), and Battaglia and Smith (I962) have shown that under competitive conditions the chromosomally polymorphic populations of Drosophila pseudoobscura are superior to the monomorphic populations. Both when the competition was due to a crowding in the larval stage and when the adults were crowded, the polymorphic populations produced more individuals and a greater biomass than did the monomorphic ones given the same amount of food. In the present investigation, a quite different measure of the population fitness is introduced. The competition by crowding is eliminated; we estimate the value $r_{m}$, which measures essentially the capacity of the population to increase in numbers of individuals under a certain set of environmental conditions.

As expected, the populations are more fit at $25^{\circ}$ than at $16^{\circ} \mathrm{C}$. (table 3 ). This does not mean, of course, that a higher temperature will always increase the $r_{m}$ values; $D$. pseudoobscura populations can be maintained in the laboratory with some difficulty at $27^{\circ}$, but as a rule not at $27 \frac{1}{2}^{\circ}$. The higher values of $r_{m}$ at $25^{\circ}$ than at $16^{\circ}$ are due to the more rapid development, and to the at least equal egg laying rate during the early part of the adult life at the higher temperature. More interesting is the increase with time of the $r_{m}$ values in most of the populations at $25^{\circ}$. This must be ascribed to the adaptation of the populations to the environment of the population cages, rather than to the attainment of the equilibrium frequencies of the chromosomal polymorphs. In fact, the increase in $r_{m}$ was more prominent in the chromosomally monomorphic than in the polymorphic populations (tables 2 and 3). Particularly noticeable is the improvement in the monomophric PP populations, which had originally the lowest fitness. This improvement has occurred both at $25^{\circ}$ and at $16^{\circ}$, although the population cages were maintained at the former temperature.

Comparison of the $r_{m}$ values in the different populations shows that the polymorphic populations are usually superior to the monomorphic ones with similar histories and tested simultaneously (tables 2 and 3). This is consistent with the behaviour of the chromosomes with different gene arrangements within the populations kept at $25^{\circ}$. The heterokaryotypes usually exhibit, at that temperature, heterosis, and consequently a population which includes heterokaryotypes may be expected to be fitter than the one consisting entirely of homokaryotypes. At $16^{\circ}$ the heterotic advantage of the heterokaryotypes over 
the homokaryotypes is, however, weak or absent (Wright and Dobzhansky, 1946). In agreement with this, the polymorphic $\mathrm{AR}+\mathrm{CH}$ populations are not superior to the monomorphic AR (Piñon) populations (table 3 ).

A closer analysis discloses, however, several facts which could not have been predicted from the known behaviour of the chromosomes within the populations. As shown in table $\mathrm{r}$, the PP chromosomes are eventually eliminated in competition with AR. This confirms the observations on the same chromosomes made earlier by Dobzhansky (1957) and by Lewontin (1958). The AR/PP heterokaryotype should accordingly not be superior to the AR/AR homokaryotype, even at $25^{\circ}$. Nevertheless, the polymorphic $A R+P P$ populations have, both at $25^{\circ}$ and at $16^{\circ}$, higher $r_{m}$ values than the monomorphic $\mathrm{AR}$, and these latter higher than the monomorphic PP. Thus, the effect of the natural selection on the karyotype frequencies in the polymorphic $\mathrm{AR}+\mathrm{PP}$ populations is to make those populations evolve towards a composition with a lower $r_{m}$ value. This can be seen most clearly in table 3. In 1961, when the frequency of PP chromosomes in the polymorphic populations was high, the $r_{m}$ value for these populations was 0.209, and for AR (Mather) populations 0.Ig8 (table 3). A year later, in 1962 , the frequency of PP in the polymorphic populations was low (about 5 per cent.), but the $r_{m}$ rose to 0.219 , while in the monomorphic AR populations it rose to 0.215 . The net superiority of the polymorphic populations was, hence, $0.01 \mathrm{I}$ in I96I and only 0.004 in 1962. With the loss of PP chromosomes, the $r_{m} \mathrm{~s}$ in the polymorphic and the monomorphic populations converge, as expected. A similar phenomenon was observed by Lewontin and Matsuo (1963), in Drosophila busckii, where a genotype which was superior in mixed cultures had a lower viability in pure cultures.

Our conclusion must be that, although in broad outline there is a correspondence between the relative fitness of the karyotypes within the populations and the population fitness as measured by the $r_{m}$, there may be, in particular cases, no relation or even an inverse relation between these measurements. This may indicate that the value $r_{m}$ is unduly influenced by variables which do not have a proportionate ecological importance in nature. As pointed out above, in our experiments the $r_{m}$ is correlated with the rate of egg laying during the early part of the adult life, less so with the longevity or with rates of egg laying at older ages, and very little, at a given temperature, with the development rate and with the viability. Similarly, in the experiments of Beardmore, Dobzhansky and Pavlovsky (1960) and Dobzhansky and Pavlovsky ( $196 \mathrm{I}$ ), there was no indication of heterosis in polymorphic populations with respect to the mean body size or body weight of the adult flies, but a clear heterosis in the numbers of individuals and in the biomass produced.

The relative fitness of populations, like that of genotypes within a population, is not the same in different environments. Comparisons 
of fitness should, ideally, be made over the entire range of the environments to which the populations, or the genotypes, are exposed, and should also take into account the incidence of these environments in the natural habitats of the species. This ideal is hardly ever attainable; working with Drosophila, the experiments are made in environments which are not exactly like any that the flies inhabit in nature. It is, then, rather remarkable that in almost all the environments in which the chromosomally polymorphic and monomorphic populations were compared in the experiments of Beardmore, Dobzhansky and Pavlovsky (see above), as well as in the present ones, the results showed as consistently as they did that the polymorphic populations were superior to the monomorphic ones.

\section{SUMMARY}

Ten experimental laboratory populations of Drosophila pseudoobscura, four of them polymorphic and six monomorphic for gene arrangements in the third chromosomes, were examined for the rates of survival and the duration of the development from egg to adult, and for the longevity and the fecundity of the females at different ages. These observations were used to compute the value $r_{m}$, the innate capacity for increase, of the populations examined. The observations were run at two temperatures, $25^{\circ}$ and $16^{\circ} \mathrm{C}$., and were repeated in 1961 and in 1962 , when the populations were only beginning, and after they had had some time to adapt to the living conditions in the population cages.

By and large, the $r_{m}$ was higher in the polymorphic than in the corresponding monomorphic populations, the superiority of the polymorphic ones being generally more pronounced at $25^{\circ}$ than at $16^{\circ}$. This superiority did not depend equally on all the components of the $r_{m}$, but chiefly on a greater fecundity of the females from the polymorphic populations. The $r_{m}$ value has increased in most populations between 1961 and 1962 , the increase being especially striking in the populations which had the lowest $r_{m}$ in $196 \mathrm{I}$. The increase depended again chiefly on a higher fecundity, while the duration of life has, on the contrary, declined in at least some of the populations. As a measure of the fitness of a population, the $r_{m}$ value has both virtues and limitations.

Acknowledgments. - This work could not have been completed without the conscientious help of Mrs Angela Drescher and Dr K. Sankaranarayanan in making some of the counts, and of Mrs M. E. Gabrusewycz and Mrs M. L. Fungairiño de Torroja who made most of the calculations. It was begun at the Department of Zoology, Columbia University, and completed at the Rockefeller Institute, New York City. The statistical analysis has been carried on at the University of Rochester with the help of Mrs M. J. Lewontin.

\section{REFERENCES}

anderwartha, H. G., AND Birch, L. C. 1954. The Distribution and Abundance of Animals. Chicago University Press. 


\section{TH. DOBZHANSKY, R. C. LEWONTIN AND O. PAVLOVSKY}

BatTaglia, B., AND SMith, H. 1961. The Darwinian fitness of polymorphic and monomorphic populations of Drosophila pseudoobscura at $16^{\circ}$. Heredity, 16 , $475-484$.

BEARDMORE, J. A., DOBZHANSKY, TH., AND PAVlovsky, o. A. ig6o. An attempt to compare the fitness of polymorphic and monomorphic experimental populations of Drosophila pseudoobscura. Heredity, 14, 19-33.

BIRCH, L. C., DOBZHANSKY, TH., ELliotT, P. O., AND leWONTIN, R. G. 1963. Relative fitness of geographic races of Drosophila serrata. Evolution, $17,72-83$.

Dobzhansky, тн. 1957. Mendelian populations as genetic systems. Cold Spring Harbor Symposium Quant. Biol., 22, 385-393.

DOBzHANSKY, тн. 1961. On the dynamics of chromosomal polymorphism in Drosophila. In J. S. Kennedy (Ed.) Insect polymorphism, Roy. Entom. Soc. London.

DOBZHANSKY, TH., AND PAvLOVSKY, O. A. 1961. A further study of fitness of chromosomally polymorphic and monomorphic populations in Drosophila pseudoobscura. Heredity, $16, \mathrm{1} 69-\mathrm{I} 77$.

Doвzhansky, тH. 1963. Genetics of natural populations. XXXIII. A progress report on genetic changes in populations of Drosophila pseudoobscura and Drosophila persimilis in a locality in California. Evolution, 17, 333-339.

DOBzhansky, тH. 1964. How do the genetic loads affect the fitness of their carriers in Drosophila populations? Amer. Natur., $98,5^{1-166 . ~}$

Fisher, R. A. 1930. The Genetical Theory of Natural Selection. Oxford University Press.

LEWONTIN, R. C. 1958. Studies on heterozygosity and homeostasis. II. Loss of heterosis in a constant environment. Evolution, 12, 494-503.

LEWONTIN, R. G., AND MATSUO, - Y. 1963. Interaction of genotypes determining viability in Drosophila busckii. Proc. Nat. Acad. Sci., 49, $270-278$.

LOTKA, A. J. 1925. Elements of Physical Biology. Williams \& Wilkins, Baltimore.

STRICKBERGER, M. W. $\mathrm{r}^{6} 6_{3}$. Comparative fitness of experimental populations of Drosophila pseudoobscura. Heredity, I8, 385-395.

tantawy, A. o. $196 \mathrm{r}$. Developmental homeostasis in populations of Drosophila pseudoobscura. Evolution, 15, I32-144.

tantawy, A. O., AND vetukhiv, M. O. I96o. Effects of size on fecundity, longevity and viability in populations of Drosophila pseudoobscura. Amer. Natur., 94, 395-404. WRIGHT, s., AND DOBZHANSKY, TH. 1946. Genetics of natural populations. XII. Genetics, 3I, 125-I56. 